\title{
ETNICIDADE, SUBCLASSE E EXCLUSÃO SOCIAL: UMA COMUNIDADE CIGANA EM OLEIROS-VILAVERDE - NOROESTE DE PORTUGAL
}

https://doi.org/10.17979/relaso.2011.1.1201

\section{Manuel Carlos Silva* Susana Silva**}

\section{Resumo:}

Neste artigo os autores, partindo de resultados de estudos, inquéritos, sondagens e de um pequeno estudo etnográfico realizado em Oleiros, concelho de Vila Verde, uma comunidade do noroeste de Portugal, constatam a persistência de preconceitos e discriminações por parte de portugueses não ciganos para com ciganos portugueses. Tais factos indiciam que Portugal, apesar de ser multicultural e ter registado alguns avanços em termos seculares na relação com a minoria cigana secularmente presente, perseguida, estigmatizada, tem ainda dificuldade em lidar com a diferença, convertendo esta em subalternização e tratamento discriminatório para com esta minoria.

Depois de definir e equacionar os conceitos de etnicidade, subclasse e exclusão social, os autores consideram-nos pertinentes e aplicáveis às relações sociais entre maioria não cigana e minoria cigana, não obstante a relativa ambiguidade nomeadamente dos conceitos de subclasse e exclusão social. Perante as formas de exclusão social nas suas formas institucional e social e, eventualmente, a condescendência paternalista ou o multiculturalismo benigno, importa salientar a necessidade de contrapor um multiculuralismo crítico aliado a um combate às diversas formas de discriminação e racismo não só flagrante como subtil.

Palavras-chave: ciganos, etnia, subclasse, a exclusão social, discriminação

\section{Resumo em inglês}

In this article the authors, from results of studies, surveys and of small ethnographic study conducted in Oleiros, in the 
municipality of Vila Verde - a community northwest of Portugal - verify the persistence of prejudices and discriminations by non-gypsies Portuguese toward portuguese gypsies. These facts indicate that Portugal, despite being multicultural and have been realised some political-juridical advances in relation to the Gypsies minority, persecuted, stigmatized, still has difficulty to deal with the difference, turning this into subordination and discrimination towards this minority.

After a definition and analisis of the concepts of ethnicity, underclass and social exclusion, the authors consider them relevant and applicable to most social relations between nonGypsies Portuguese Gypsies minority, despite the relative ambiguity of such concepts as underclass and social exclusion. In face of forms of social exclusion and their institutional and social forms, and eventually the paternalist attitudes in context of a benign multiculturalism, it should be noted the need to counter a critical multiculuralism combined with a fight to the various forms of discrimination and racism not blatant racism but also subtle.

Keywords: Gypsies, ethnicity, underclass, social exclusion, discrimination

\section{Introdução: alguns dados e o problema}

Inquéritos e sondagens levados a cabo não só em países centrais europeus como também em Portugal mostram que $30 \%$ dos cidadãos admitem ter preconceitos raciais contra emigrantes sobretudo africanos e cerca de $60 \%$ acham que os emigrantes estão a mais ou, em Portugal, cerca de 2/3 não gostariam de viver junto dum acampanhamento de ciganos, $36,4 \%$ afirmavam ter por eles antipatia, 54\% não gostariam de ver um(a) filho(a) casar-se com um(a) cigano(a), a maioria confessou haver ciganos a mais em Portugal e três quartos dos inquiridos responderam que os ciganos têm muita ou 
bastante tendência para roubar, cometer actos violentos ou traficar droga. 1

A (re)emergência de relações conflituais, sobretudo na última década, estabelecidas entre diversas comunidades autóctones e minorias étnicas em Portugal tem vindo a desafiar a imagem de um "Portugal multicultural" (Bastos e Bastos 1999), a qual não é contudo pacífica. Enquanto uns alertam para ameaças e práticas de discriminação racial no quadro de um Estado-Nação mono-étnico e homogéneo como Portugal, outros preferem salientar a baixa densidade e fraca visibilidade social e politica de conflitos raciais e étnicos em Portugal.

A partir de um conflito entre uma comunidade rural nortenha e uma comunidade cigana em Oleiros-Vila Verde no Noroeste de Portugal, procuramos problematizar a suposta (con)vivência multicultural em Portugal, sobretudo através da análise das intervenções dos poderes locais e nacionais, confrontando-as com as especificidades económicas e etnoculturais destas comunidades. Por estes e outros exemplos, mesmo quando eles não assumam o alcance e a dimensão que constatamos noutros países, regiões ou cidades europeias, estamos, pelos dados recolhidos, perante a (re)emergência de preconceitos racistas e formas de discriminação racial. Como se compreendem e explicam então tais formas de discriminação e racismo, apesar do discurso internacional dos direitos do Homem, onde é proclamada a igualdade de tratamento, independentemente do sexo, da cultura, da religião ou da raça?

Deixando agora de parte as teorias biogenéticas e sociobiológicas sobre o racismo - as quais cada vez têm menor credibilidade não só científica como social e moral - relevam, por um lado, algumas interpretações de cariz

1 Cf. Giddens (1989). Para o caso português, ver J.M. Fernandes in Público 28/81996 a 16/9/1996. Este texto constitui parte integrante de um relatório do projecto "Do racismo e da xenofobia ao multiculturalismo" - de que é responsável o primeiro autor -, em que a recolha dos dados empíricos e trabalho de campo foi realizado pela segunda autora no quadro do seu estágio curricular, o que deu llugar a uma primeira publicação (Silva e Silva 2002). 
sociopsicológico - que tendem a explicar o preconceito racial com base em predisposições psíquicas ou como resultante de repressões e frustrações no processo de socialização - e, por outro, algumas teorias sociológicas. Entre estas últimas, haveria que distinguir (i) certas teorias conservadoras que apelam a conceitos orgânicos de 'vinculos primordiais', constitutivos de determinada pertença étnica ou cultural; (ii) as concepções liberais, que, orientando-se em função da discriminação nas relações face a face, vêem o racismo resultante da insuficiente adequação jurídico-política; (iii) a visão (neo)weberiana que tende a explicar o racismo com base nas relações assimétricas de poder e/ou estratificação social; (iv) a visão radical e socialista com base nas relações de produção e dominação capitalistas ${ }^{2}$

Se a última concepção de inspiração marxista apresenta maior consistência, ela é ainda insuficiente na medida em que não dá suficientemente conta de contextos nem avança, tal como o faz Bader (1995), como veremos, conceitos específicos e condições de estruturação do conflito racial, os quais permitam compreender e explicar os fenómenos de discriminação e racismo, para o que se impõe uma articulação hierarquizada do nível socio-estrutural destacado pela abordagem (neo)marxista com o nivel organizativo e de poder sublinhado basicamente pela perspectiva (neo)weberiana, podendo e devendo enriquecer-se inclusive com elementos de cariz interactivo provindos das teorias da interacção social

\section{Etnicidade, exclusão social e acção política}

Etnia, em sentido restrito, designa, segundo Bretton (1983:11ss), o conjunto de indivíduos pertencentes à mesma língua materna e, em sentido amplo, compreende uma comunidade de indivíduos ligados por traços comuns linguísticos, antropológicos, históricos, políticos, culturais e religiosos.

2 Para desenvolvimento destas teorias e referências aos seus respectivos defensores, cf. Bader 1995, Silva (2000) 
A par ou em articulação com outras formas de desigualdade (classe, género, idade), etnicidade constitui um dos principais eixos de diferenciação social, clivagem cultural e política e, não raro, dando lugar à "etnicização" da exclusão social (cf. Fernandes 1995), tal como o sublinha Wieviorka (1992:214). Os grupos étnicos dominantes, sobretudo quando confrontados a viver numa área residencial partilhada com grupos étnicos minoritários, sentem-se entalados entre a necessidade de respeitar os valores da democracia plural (liberdade, justiça, igualdade) e o sentimento de rejeição para com esses grupos étnicos considerados estranhos e outsiders, sobretudo quando partem do pressuposto que estes são concorrentes e vêm ameaçar a sua posição.

Se, por um lado, a retórica oficial proclama o imperativo de integração e promoção das minorias étnicas, sempre que membros destas acedem a determinados recursos, lugares ou espaços, nomeadamente em meio urbano, e conhecem uma caminhada num sentido ascendente, emergem ressentimentos e fenómenos de resistência por parte de membros da maioria, sobretudo quando, perante a 'concorrência' de membros das minorias, se sentem ameaçados, vulneráveis ou precarizados. Estas reacções, por sua vez, incitam à revivescência e ao reforço da identidade cultural por parte das minorias étnicas, que realimentam o sentimento de pertença pela preservação dos seus traços identitários, o que contribui para manter e até reforçar processos de distanciamento, quando não de separação e exclusão social interétnica e, assim, gerar-se uma potencial eclosão de conflitos. Com efeito, um grupo étnico, sempre que separado social e economicamente dos demais ou quando, como enfatiza Giddens (1989), se apresenta como distintivo pelas suas origens, vínculos de pertença e práticas culturais, demarca-se de e/ou é demarcado por outros grupos nas suas relações interétnicas, as quais poderão caracterizar-se ora por co-presença e coexistência, ora por distância e exclusão, ora ainda por afrontamento e hostilidade. As estratégias de preservação das identidades étnicas reforçam-se, sempre que as minorias são alvo de processos de exclusão no país de acolhimento ou por parte da etnia dominante, fazendo 
emergir o que Weber (1978:303) denominava comunidade negativamente privilegiada e Myrdal (1944) designava de subclasse étnica. ${ }^{3}$ Este conceito em Myrdal foi construído a partir da existência de categorias étnicas que sofriam de privação relativa num contexto de pobreza e/ou exclusão social. Segundo Bader (1993, 1995), para que um movimento étnico se torne eficaz, importa: (i) que os respectivos actores da etnia dominada sejam, de facto, vítimas de processos de exploração e/ou dominação em estruturas e contextos específicos por parte de instituições e grupos dominantes; (ii) que haja desequilíbrios no acesso e no controlo de recursos e recompensas e que os grupos minoritários sejam percebidos como "ameaçadores" e "usurpadores" de "direitos" e "privilégios" da maioria; (iii) que o grupo étnico dominado possua uma identidade própria e partilhe costumes, hábitos e estilos de vida específicos e diferentes dos da maioria; (iv) que os respectivos grupos étnicos - dominante e dominado detenham ideologias e/ou utopias específicas; $(v)$ que ambos

3 Era aliás aos grupos desprivilegiados, quase párias, que, vivendo em "comunidades desprezadas", Weber (1978) se referiu e tipificou na sua classificação de classes. O conceito poder-se-ia aplicar à etnia cigana, considerando a situação secular desta minoria étnica, tal como a descrevem e analisam, entre outros, Sán Román (1986), P. Machado (1994), Cortezão e F. Pinto (1995), A Castro (1995). Com o conceito de suclasse étnica desenvolvido por Myrdal (1944) e, mais recentemente, por outros autores da área anglosaxónica, sobretudo desde os anos setenta, procurou designar-se a relativa posição de desvantagem social e económica em que se encontra(va)m membros de minorias étnicas, para o que contribuem as definições e classificações dos membros da maioria, incluindo os das classes populares. Apesar das reservas ao conceito de subclasse por atribuir a responsabilidade das privações e exclusões aos próprios membros desta, creio, porém, com Giddens (1989) que o conceito é relevante na sobreposição analítica entre discriminação étnica e sujeição de classe. Há, porém, no entanto, que referir que o conceito não é especificamente aplicável às minorias étnicas, podendo sê-lo a grupos que se encontrem em situação de destituição, pobreza ou exclusão, cujos membros se tornam incapazes de potenciar a seu favor oportunidades de vida em termos sociais, escolares ou laborais, vivendo, em regra, dependentes de subsídios estatais ou doutras instituições. 
consigam organizar-se e mobilizar recursos internos e externos para negociar e/ou fazer face em caso de confronto.

Hoje que o racismo biológico, senão totalmente abandonado, foi relegado para segundo plano, ressurge uma outra forma de racismo - o cultural -, desembocando na 'nacionalização das identidades' e na racialização da vida social e política, tal como o têm apontado autores como Banton (1979), Balibar \& Wallerstein (1988), Wieviorka (1992), Memmi (1993), Gellner (1993) e Miles (1995). O neoracismo não só professa, de forma sofisticada, a distanciação e utiliza linguagem (pseudo)'etnológica', como também invoca, de modo subtil, o direito à identidade própria e à especificidade cultural dos grupos racizados. Os defensores do neoracismo, embora afirmem prezar outras culturas da mesma forma que a sua própria, não deixam de denotar comportamentos xenófobos e discriminatórios quando essas culturas outras supostamente ameaçam a sua.

\section{Comunidade cigana em Oleiros: os poderes locais e a população}

Dada a tradicional não integração dos ciganos em modos de vida convencionais e dadas as dificuldades e barreiras de selecção no sistema educativo, bem como as desiguais oportunidades no acesso ao emprego e/ou à criação de empresas, a grande maioria dos membros das comunidades ciganas nomeadamente a de Oleiros vivia, em termos de emprego, em posições marginais, instáveis e precárias nos sectores do artesanato, da venda de cavalos e nas feiras ambulantes ${ }^{4}$. Além de se encontrarem tradicionalmente nestas franjas do mercado paralelo, quando assalariados, tinham amiúde ocupações pior remuneradas, não eram objecto de igual tratamento e protecção perante a lei e eram não raro alvo de discriminação por parte de agentes das várias instituições. Neste caso constituíam-se em mundos isolados, separados ou até segregados em ghetto, cuja baixa ou nula comunicação com membros das comunidades autóctones provocava junto destas sentimentos

4 Já o mesmo havia sido constatado poer diversos autores entre os quais Rex 1986:111-112, Machado 1992:129. 
de insegurança e medo, o que reforçava os processos de rotulagem e estigmatização das minorias étnicas.

Esta comunidade cigana que comprara um terreno para acampar foi obrigada pelas autoridades nomeadamente camarárias a abandonar o terreno que lhes pertencia sob pretexto de proibição de contrução naquele local e sob a alegada razão da protecção e segurança das famílias de Oleiros. Por outro lado, aduzia-se que se tratava de um local de tráfico de droga, pelo que os ciganos eram intimados a sair daquele local, tendo-se verificado no verão de 1996 um levantamento popular com anuência (ou mesmo incitamento) das autoridades locais. À excepção do então Governador Civil de Braga, secundado por vozes provenientes de diversos quadrantes civis, políticos e religiosos, o processo em torno do levantamento popular contra os ciganos em Oleiros terá constituido uma longa e interminável processo de desresponsabilização com a passagem de 'culpas' das instâncias centrais para as periféricas e destas para a população e vice-versa. Assiste-se, por parte da população local, à progressiva desconfiança popular em relação ao Estado de Direito, associado ao clima de suspeição e desautorização das próprias forças policiais. As acções de rejeição e segregação da comunidade cigana em Oleiros e outras freguesias minhotas nem sequer foram consideradas manifestações racistas, sobretudo por parte de politicos locais, concelhios ou distritais para quem o que estava em jogo era a defesa da identidade da população autóctone e a sua segurança perante alegadas ameaças originárias do suposto tráfico de droga levado a cabo por membros da comunidade cigana. Independentemente das diversas interpretações tributárias dos vários paradigmas teóricoideológicos, foi relevante inferir, da parte duma grande maioria dos habitantes de Oleiros, um elevado grau de preconceitos e generalizações abusivas acerca dos ciganos e mesmo algumas práticas de discriminação racista para com esta minoria secularmente perseguida e excluída da plenitude dos seus direitos de cidadania.

A acentuação dos estereótipos negativos sobre as minorias étnicas exprime e reflecte a exclusão/rejeição destas 
por parte considerável dos membros do grupo étnico dominante. Se, por um lado, tais atitudes incitam as comunidades das minorias étnicas a reforçar a sua identidade, refugiando-se nela para alimentar um sentimento de pertença e coesão de grupo e para garantir a sua reprodução social, tal reforço identitário acentua, por sua vez, a exclusão a que são sujeitos, funcionando estes mecanismos, como refere Pinto (1995:37-51), num sentido circular.

\section{Tensão interétnica, exclusão social e Estado}

A tensão vivida pelas minorias étnicas entre integração e exclusão encerra contradições que reflectiam as da própria comunidade autóctone face a elas, pois esta deseja a integração daquelas, mas simultaneamente reage, subalternizando-as e confinando-as, por exemplo, à ocupação de determinado espaço geo-social. Como diz Wieviorka (1993), as relações entre maiorias autóctones e minorias étnicas lançam importantes desafios à democracia e exigem, como referem Pierré-Caps (1995) e Rex (1988), uma nova gestão política, uma vez que determinadas situações históricas e actuais têm demonstrado que a identidade étnica, denotando um sentimento de corpo, tem constituido uma fonte de clivagem social tão ou mais importante como a pertença de classe a qual obriga a um ajustamento racional de interesses.

$\mathrm{O}$ reconhecimento jurídico do direito à diferença em relação às minorias étnicas embate aparentemente com o princípio da igualdade de tratamento de todos os cidadãos do Estado. Porém, este objectivo, em diversas situações, só poderá ser alcançado se se praticar uma política de discriminação positiva, contrariando assim o tradicional modelo político do Estado-Nação. Para tal, há que separar, como propõe Pierré-Caps (1995), a nação do Estado, pois um certo nacionalismo, ao reclamar uma unidade política territorial etnicamente homogénea, só se poderá tornar exequivel a expensas da assimilação, da expulsão ou da matança de todos os não-nacionais. Mas o autor vai mais longe, concluindo que um Estado multinacional reclama uma 
democracia renovada, sugerindo que esta poderia ser induzida pela "democracia associativa", onde através da partilha do poder político e dum destino comum seja possivel integrar a multinação numa estrutura estatal estável.

Porém, esta situação implica, além da reavaliação conceptual do conceito central de etnia, a interpelação crítica perante certas atitudes negativas sobre as etnias minoritárias, nomeadamente a exclusão e a condescendência. Excluir da sociedade a minoria 'desviante', quer através da rejeição (v.g. recusa do seu reconhecimento, politicas de assimilação forçada), quer da eliminação/extermínio, significa que as maiorias dominantes representam-se e apresentam-se amiúde como entidades detentoras de "direitos" primeiros face às minorias étnicas. Mais, revelam uma resistência fantástica e até fantasmagórica em relação a tudo o que contradiz os seus interesses económicos, politicos e ideológicos estabelecidos e/ou põe em causa a ideia que fazem de si próprias, tal como o argumentaram Elias e Scotson (1963) e Wieviorka (1993:179).

A condescendência é uma atitude menos intolerante e radical que a exclusão mas traduz-se, em termos estratégicos de médio-longo prazo, numa perspectiva assimilacionista. Porém, esta é, por excelência, a ideologia dominante dos grupos estabelecidos (ingroups) que acreditam poder incorporar todos os de fora (outgroups), ideologia essa aliás bem visivel, quer no discurso corrente, quer no discurso dos meios de comunicação social.

Com esta atitude de condescendência paternalista se prendem algumas variantes de certo interculturalismo que Stoer e Cortesão (1999) denominam de 'multiculturalismo benigno' e que poderiamos também designar de interculturalismo táctico que, a curto prazo, visa evitar de modo paternalista clivagens e rupturas mas, estrategicamente e a longo prazo, pretende conseguir a incorporação ou fusão dessas minorias étnicas na maioria. ternalista e desigual, é necessário que cada uma das culturas se auto-interprete, aprenda a conhecer os seus limites e dialogue com as demais, o que implica desenvolver um 
multiculturalismo progressivo e crítico (Santos 1995, Taguieff 1995).

A razão ocidental assume que foi ela a produtora de principios universalistas tais como o discurso internacional dos direitos do Homem, esquecendo-se que as suas concepções de universal traduzem não raro uma concepção do universal que não passa dum narcisismo autocontemplativo, autoelogioso e incapaz de dialogar criticamente com minorias étnicas e culturais. Como poderão as minorias étnicas encontrar o seu lugar no sistema ocidental que, pretendendo-se universalizante, é produzido pela específica razão ocidental? Ou não será que esta razão ocidental, porque se alimenta do poderio económico e político, se permite arrogar um pretenso universalismo "racional"?

Uma sociedade pluricultural não só exige que uma cultura política de direitos iguais no domínio público, como também reclama o livre curso da tolerância e do reconhecimento da língua, da religião, dos costumes familiares e da cultura das minorias no domínio privado. Países assentes nos princípios do Estado de Direito têm desenvolvido alguns mecanismos contra o racismo flagrante, frontal e agressivo. Contudo, têm surgido, nas últimas décadas, tendências de racismo subtil, o qual, segundo recentes investigações na área da sociologia e da psicologia social, é, do ponto de vista cognitivo, relativamente coerente, não se tratando de uma tomada de posição consciente mas mais de um processo subconsciente ou inconsciente (cf. Pettigrew e Meertens 1995:127, Vala 1999).

Hoje, a corrente dominante em torno das questões interétnicas caminha justamente no sentido de denominada inclusão social das minorias étnicas, pretendendo, num segundo momento, integrá-los nos parâmetros políticos vigentes e, em última instância, assimilá-los nas culturas dominantes. Tais politicas, supostamente mais humanistas e democráticas do que a exclusão ou reclusão sociais, para além de não se produzirem tão rapidamente os efeitos desejados, são contudo confrontadas com principios duma multiculturalidade crítica que pressupõe o respeito pela 
respectiva identidade étnica e pelo reconhecimento dum espaço de afirmação política próprio.

\section{Conclusão}

Do exposto se infere não só ser necessário contrariar os preconceitos e as formas de racismo subtil entre os cidadãos da maioria autóctone dominante como também exigir-se aos Estados europeus, em nome do princípio constitucional da igualdade de tratamento, uma nova atitude para com as minorias étnicas incluindo obviamente as comunidades ciganas. Por seu turno, os preconceitos, os estereótipos e as representações sociais negativas - evidenciadas em certos momentos em práticas sociais racizantes ou até racistas não só bloqueiam a comunicação entre as minoria étnicas e a maioria autóctone, como também são um factor de incompreensão mútua, pelo que se revela indispensável descristalizar tais imagens para que atitudes, comportamentos e políticas condignas possam firmar-se. Dum considerável grau de práticas discriminatórias e representações racistas não é pertinente deduzir concepções essencialistas em torno do racismo como se este fosse uma espécie de propriedade intrínseca de determinadas pessoas ou grupos, enquanto outras/os seriam imunes a tal. Ele é o resultado de determinadas estruturas e contextos específicos, de relações sociais assimétricas perpassadas de etnocentrismo e dominação de uns grupos sociais sobre outros, caracterizadas por contrastes de identidades, culturas e estilos de vida entre dominantes e dominados.

O combate ao racismo depara-se com diversas dificuldades: por um lado, os arraigados preconceitos arraigados, não raro reforçados por certos líderes nacionais e locais eivados de visões etnocêntricas e preocupados em manter os seus poderes e, por outro, uma desresponsabilização institucional, acompanhada de uma ineficácia política devida à inércia e/ou relaxação de representantes de diversas instituições (para)estatais. São pois necessários avultados investimentos no parque habitacional, na rede sócio-cultural, educativa, quer dentro, 
quer fora das escolas, de modo a educar não só as minorias mas também a maioria autóctone para uma cidadania activa e multicultural.

Revela-se, assim, urgente reconstruir espaços sociais e políticos que permitam a aceitação e o reconhecimento do diferente ou do estranho, da sua identidade socio-cultural, dos seus modos de vida para, a partir daí, obter vivências reais de multiculturalidade, sem que tal implique a subordinação ou subalternização de uma cultura pela outra. Mas tal só poderá ocorrer no quadro do já referido multiculturalismo estratégico e crítico e não apenas táctico. Contrariamente a posições radicalizadas que assumem que só no quadro duma sociedade socialista será possível realizar uma sociedade multicultural, importa contudo entretanto apontar para algumas pistas a curto e médio prazo: estabelecer pontes de comunicação entre membros da maioria e minoria, denunciar agressões e violências raciais, estimular a criação de escolas e professores multiculturais que combatam preconceitos, apelar à responsabilidade de organizações políticas e associações cívicas, dos cidadãos e, em particular, de determinados grupos sociais importantes na formação da opinião pública (organizações políticas, politicos, intelectuais, jornalistas, líderes locais).

\section{Bibliografia}

+ALMEIDA, João Ferreira de et al. (1992), Exclusão social. Factores e tipos de pobreza em Portugal, Oeiras, Celta Editora. +BADER, Veit (1993), "Citizenship and Exclusion" in Citizenship and Local Justice, Amesterdão

+BADER, Veit (1995), Rassismus, Ethnizitat, Burgerschaft. Sociologische und Philosophische Uberlegungen Munster, Westalisches Dampfboot.

+BALIBAR, Étienne e WALLERSTEIN, Immanuel (1988), Race, Nation, Classe: Les identités ambigues, Paris, La Découverte. 
+BANTON, Michael (1979), A ideia de raça, Lisboa, Edições 70.

+BASTOS, J. Gabriel Pereira e BASTOS, Susana (1999), Portugal multicultural, Lisboa: O Fim do Século.

+BRETON, Roland (s/d), As etnias, Porto, Rés-Editora.

+CORTESÃO, Luíza, PINTO, Fátima (orgs.) (1995), O povo cigano: cidadãos na sombra. Processos explicitos e ocultos de exclusão, Porto, Edições Afrontamento.

+ELIAS, Norbert e SCOTSON, J. L. (1963), The Established and the Outsiders, Londres.

+FERNANDES, José Manuel, "Obrigado, senhor governador" in Público, 30/08/96.

+GELLNER, Ernest (1993), Nações e Nacionalismo, Lisboa, Gradiva.

+GIDDENS, Anthony (1989), Sociology, Oxford:Polity Press.

+MACHADO, Fernando (1992), "Etnicidade em Portugal contrastes e politização" in Sociologia - Problemas e Práticas, 12: 123-136.

+ MEMMI, Albert (1993), O racismo, Lisboa, Caminho.

+MILES, Robert (1995), "Racismo institucional e relações de classe: uma relação problemática", in M.WIEVIORKA (org.), Racismo e modernidade: actas do Colóquio "Três Dias sobre o Racismo", Venda Nova, Bertrand: 161-177.

+PETTIGREW, Thomas F., MEERTENS, R. W. (1995), "O racismo velado: dimensões e medidas" in $M$. WIEVIORKA (org.), Racismo e modernidade: actas do Colóquio "Três Dias sobre o Racismo", Venda Nova, Bertrand: 111-128.

+PIERRÉ-CAPS, Stéphane (1995), A Multinação - o futuro das minorias étnicas na Europa Central e Oriental, Lisboa, Instituto Piaget.

+PINTO, Fátima (1995), "Etnia Cigana - realidade sóciocultural múltipla e dinâmica" in L. CORTESÃO, F. PINTO (orgs.), $O$ povo cigano: cidadãos na sombra. Processos explícitos e ocultos de exclusão:37-51, Porto, Edições Afrontamento.

+REX, John (1988), Raça e etnia, Lisboa, Editorial Estampa.

+REX, John (1995), "Estratégias anti-racistas na Europa" in M. WIEVIORKA (org.), Racismo e modernidade: actas do 
Colóquio "Três Dias sobre o Racismo":283-300, Venda Nova, Bertrand.

+SAN-ROMÁN, Teresa (org.) (1986), Entre la marginación y el racismo. Reflexiones sobre la vida de los gitanos, Madrid: Alianza Editorial.

+SANTOS, Boaventura de Sousa (1995), Toward a New Common Sense, Law, Science and Politics in the Paradigmatic Transition, Londres, Nova Iorque: Routledge \& Kegan Paul. +SILVA, Manuel Carlos (2000), "Racismo e conflitos interétnicos: elementos para uma investigação" in Revista Critica de Ciências Sociais, 56:41-63.

+STOER, Stephen e CORTESÃO, Luísa (1999), Levantando a Pedra, Porto: Afrontamento.

+TAGUIEFF, Pierre-André (1995), "O anti-racismo em crise. Elementos duma critica reformista" in M. WIEVIORKA (org.), Racismo e modernidade: actas do Colóquio "Três Dias sobre o Racismo":308-344, Venda Nova, Bertrand.

+VALA, Jorge (1999), Novos racismos, Oeiras: Celta

+WIEVIORKA, Michel (1992), El espacio del racismo, Barcelona, Paidós.

+WIEVIORKA, Michel (1993), A democracia à prova: nacionalismo, populismo e etnicidade, Lisboa, Instituto Piaget. WIEVIORKA, Michel (1995), "Introdução" e "Conclusão: antiracismo, democracia e identidades" in M WIEVIORKA (org.), Racismo e modernidade: actas do Colóquio "Três Dias sobre o Racismo",:9-22 e 361-373, Venda Nova, Bertrand

\section{FORMA DE CITAR ESTE TRABAJO EN BIBLIOGRAFIAS HOW TO CITE THIS ARTICLE IN BIBLIOGRAPHIES}

Silva, M. C. e Silva, S. (2011): "Etnicidade, subclasse e exclusão social: uma comunidade cigana em OleirosVilaverde - noroeste de Portugal", Revista Latina de Sociologia, $\mathrm{n}^{\circ} \quad 1$ 209-223, http://revistalatinadesociologia.com, ISSN 2253-6469 